\title{
Technology help seeking and help giving in an intercultural community of student life ${ }^{1}$
}

\author{
Derek Tannis, University of Alberta, Edmonton Canada \\ Email: derek.tannis@ualberta.ca
}

\begin{abstract}
This paper presents a particular aspect of 'being online': the embodied, lived experience of interacting with digital devices and computer screens, involving seeking and giving help to learn and teach skills and abilities that are often taken for granted in our "wired world". The article includes analysis and reflection on a phenomenological study involving international students who arrived at their Canadian post-secondary institutions with limited or no background using computers and the Internet. This exploration leads to an enriched perspective on technology support and training. Meaningful, hands-on, task-oriented support is revealed as an ethical intersubjective lived relation, experienced as reciprocity in an intercultural community of student life.
\end{abstract}

\section{Introduction}

On the weekends and evenings during my graduate studies, I would often go the computer lab to complete assignments. One Saturday afternoon, I entered a lab, noting there was one other student present. We exchanged greetings and I sat down to get to work. A few minutes later, the student asked me for assistance. He turned towards me, his strained expression disclosing pent up frustration. He was struggling with how to use a computer program. I sat down next to him, spent a few minutes helping him and then, for the next hour, we shared our backgrounds and plans for the future. I learned he was an international graduate student who was new to the university. Years later, when I was conducting a phenomenological study investigating the lived experience of international students' requiring, requesting and receiving help with using computers, this student shared his recollection of the moments leading up to our chance meeting.

I needed to draw some figures. I sat on the computer...how was I to go about this? [...] Wow, I rushed to the computer room here, waiting. That was a Saturday. I waited for four hours, you know? Nobody came around. It was just about around a time like this. It's quiet. I felt like weeping. Whom was I going to contact? How was I going to give this out? [...] So when that happens, you say your heart's beating, you feel like a physical reaction. It's emotional drain. It isn't that I haven't got the ideas, but the technology was beating me. It was beating me seriously and if it were at home I just would have gone to the Internet café, "Please sir I am trying to draw this, just do it for me."

Experiences such as Leo's shed light on what I have come to see as the deeply embodied and relational lived meaning of technology help seeking for international students. What does Leo

\footnotetext{
${ }^{1}$ The author would like to thank Dr. Norm Friesen for his extensive support and guidance in developing this paper.
} 
mean when he says that "technology was beating" him? What leads him to anxiously wait in a computer lab until someone might randomly show up and help him? How are his past experiences seeking help with technology influencing his perceptions and manner of seeking assistance?

Reflecting on questions such as these can help deepen our understanding of the lived meaning of international student help seeking regardless of where they arose and from whom they received assistance. Such reflection requires investigating lived experience "as we live it, rather than how we conceptualize it" (van Manen, 2003, p. 30), broadening the phenomenon of international student help seeking to extend into their intercultural community of student life, to adapt Gadamer's (1975/2004) words. This community is seen as "the life process in which a community of life is lived out” (p. 443); or, to apply Merleau-Ponty’s (1945/2004) perspective, such an investigation involves seeing community as a place where "our perspectives merge into each other, and we co-exist in a common world” (Merleau-Ponty, p. 413). Taking this approach might open us to insights that challenges institutional practices and structures that may mask social injustice, highlight a deficit approach to international student support or foster xenophobic behaviour (Crosby, 2010; Lee \& Rice, 2007; Madget \& Bélanger, 2008; Paulus, Bichelmeyer, Malopinsky, Pereira, \& Rastogi, 2005; Turner \& Robson, 2008; Unterhalter \& Carpentier, 2010). As Scutt \& Hobsen (2013) write regarding the value of qualitative, phenomenological research in higher education,

Narratives can assist research of higher education to extend the boundaries of sight beyond the usual 'things' of aligned curriculum, transition and access, effective pedagogy, improving research outputs and so on, to forgotten things, which disrupt the boundaries, not for the drama of the disruption, but for the necessity of extending the frame so that the observer is included, not just as acknowledgment of perspective, but as an intertwined part of the narrative. (p. 25).

In an era where the use of computer technology and Internet communication are expanding globally (IUT-D, 2010), the lived experience of post-secondary students' help seeking is affected significantly. Technology is integrated into nearly every aspect of student life, from maintaining and making friends, accessing course notes, to completing assignments and registering for classes. Help giving at post-secondary institutions is not only confined to course content. Rather, it is inclusive of online, web-based, computer-oriented activities, effectively "blurring boundaries" of what constitutes the learning environment (Gay \& Hembrooke, 2004, p. 53). In Idoho’s words:

[I]f I want to get the notes, I have to use the computer. [...] [I]f I have research assignment, an English class and you are supposed to research on something, I have to use the computer. [...] Even if you want to use the library, you need to use the computer to find where the book is. [...] I have no choice about it.

Formal technology help giving at post-secondary institutions therefore does not only involve IT help desk officers and computer lab assistants. It also includes librarians, faculty and student affairs personnel who help students with accessing databases, using new computer software, or completing administrative tasks. The distinction as to who alone provides technology assistance must extend to the lived relations that students experience as part of their community of student life. For this reason, in this paper, I do not specifically refer to any one position or role. Rather, I use the term "technology help provider”, which includes not only people working on 
campus in helping roles, but also family, peers and community members who provide technology assistance to students.

In this way, I invite the reader to be "an intertwined part of the narrative” as a member of, in some way or at some point in time, a community of student life (p. Scutt \& Hobsen, 2013, p. 25). This is an existential perspective, as the students' lived experiences using technology reveal lived relations of fear and anxiety to connection and belonging (Greene, 1973; Grossman, 1984). As Grossman (1984) writes:

How am I related to the things which are at hand, which are there, which are with me? I care, I am concerned. Heidegger maintains that the relation between a person and world is one of caring. [...] The being of human beings, accordingly, is care. Existence and caring are equivalent forms of being. (p. 158).

An intercultural community of student life marked by ubiquitous technology integration can be experienced variably by different individuals and across institutions. The existential nature of international students' lived experience of requiring, requesting and receiving assistance with technology may thus also be viewed as a caring/uncaring, concerned/unconcerned lived relation with peers, faculty, administrators and extended community members. Turner \& Robson (2008) speak to this broader set of lived relations in their description of existential internationalization:

Within an overall framework of international effort it seems clear that the personal engagement and positive motivations of individual people within an institution are not only essential in securing a shift to the ethnorelative position inherent in deep internationalization orientations but are also prerequisites for long-term international engagement at an institutional level. To that extent, therefore, an international institution is recognizable from within its own psyche - deep internationalization acts normatively on the values and practices of institutional communities, shifting individual and institutional orientations to existential internationalization. (p. 39)

In the following pages, I explore this phenomenon of technology help seeking and giving, emphasizing a theory of the unique, respectful of each individual student's lived experience, and aiming for tactful pedagogical advice (van Manen, 1997). In the first section, I discuss the value and critique of phenomenology as an educational research methodology. In the second section, I draw from my graduate research (Tannis, 2010) to reflect on the lived experience of technology help seeking and giving, framed by the work of Heidegger (1997), Merleau-Ponty (1945/2004) and Ihde (1990). In the final section, I return to the question of how we can inform our practice in the post-secondary sector, focusing on the integration of phenomenological approaches to staff training. I advocate a technology support and training model that respects the inter-subjective, embodied and activity-embedded nature of technology help seeking and giving. Such an approach must value, internalize and exemplify the lived meaning of relational pedagogy and reciprocity in an intercultural community of student life. 


\section{Help giving mindfulness and phenomenological inquiry}

In the post-secondary sector, students' experiences with technology can intersect in multiple ways. From a phenomenological perspective, this lived experience is both an embodied interaction with technology and an inter-subjective, relational experience that is both focused on and mediated through technology. This involves an interconnection and distinction between the description of lived experience and its inter-subjective interpretation, or lived meaning, and the method to help with its discovery. Husserl (1970/2002a; 1981/2002b) introduced two concepts which help frame this exploration: the practice of bracketing, or phenomenological reduction, and the notion of the life-world.

Husserl introduced phenomenological reduction as a means to seek the universal essences of our own and others' experiences. To uncover essences, we have to bracket, or suspend, our assumptions and biases, such that " $[\mathrm{w}] \mathrm{e}$ are forbidden to make use of the actuality of the Objective world” (1981/2002b, p.130). This includes disregarding "any critical position-taking which is interested in truth or falsity", namely concepts and facts from naturalistic sciences that predetermine a "guiding idea of an objective knowledge of the world" (Husserl, 1970/2002a, p. 172). Husserl clarifies this methodological "radical suspension of Nature" (Husserl, 1981/2002b, p. 131) by introducing the concept of the life-world (Husserl, 1970/2002a). The life-world is "a realm of original self-evidences" perceived through lived experience "in immediate presence, or, in memory, remembered as the thing itself” (p. 167). For Husserl, the concept of the life-world presents a renewed approach to exploring consciousness as embedded within, rather than defined by, a scientifically objectified world. This includes the effects of technological inventions upon our lived experience, and ultimately our scientific understanding of the life-world itself. This arises out of particular activities enabled by modern science and technology, such as the invention and proliferation of computer technology. Ubiquitous access to information and communication technologies affects our lived experience within what Ihde (1990) refers to as our technological lifeworld.

Phenomenological reduction, from an epistemological standpoint, may include the suspension or bracketing of pre-conceptions or biases that originate in racial, gendered, linguistic or able-bodied perception, among others (Ahern, 1999). Applying phenomenological reduction to one's subjectivity and inter-subjectivity with one's students can be challenging. Bracketing requires willingness and capacity to capably and habitually seek a deeper comprehension and appreciation of the lived meaning of students' lived experiences. This practice may, however, tend towards relativism or the maintenance of oppressive relations. This is considered one of the most decisive critiques of phenomenology, originating from critical theory and realist perspectives (van Manen, 1997; Donati, 2013). If our subjectivities influence the lived meanings we gain from experience or from interpreting others' experiences, then class divides, gendered relations or racism may be overlooked, neutralized, or confounded. Alternatively, if differences can only be understood subjectively, then we leave no room for shared perspectives, values and practices, including our practical and theoretical understanding of our world.

Phenomenological educational research and practice is not subjectivist, however. It is event-oriented (Friesen, 2012), and in van Manen's (1997) terms, relational and action-sensitive. As pedagogical practice, phenomenological research is geared to manifesting mindfulness, or tactfulness, in the act of teaching or helping (van Manen, 1991). It is in the act of listening, observing and reacting attentively and empathically that one is able to teach or help students 
respectfully and effectively. Thus, interpretation of lived experience in the concreteness of the lifeworld has pedagogical significance. Epistemologically, this approach views knowledge as having been constructed within and between individuals and their lifeworld. If our primary source of knowing is derived from embodied interaction in the world, it is entirely possible that our experiential knowledge of the world can both augment and contrast abstracted, factual representation. This does not negate the existence of a world independent of our experience of it. However, it helps explain how we can each come to know our world similarly and yet differently, across cultures, distances and time.

\section{Hidden potential, concealed meaning}

Irena reflected on her feelings of disorientation and lack of familiarity with the lifeworld of her new post-secondary learning environment in Canada. She recalls:

With everything, like, not only computers, but if I think of little radios and little e-fax machine, the photocopiers you guys have here. At the beginning they were so complicated, so many buttons, so many functions, so many things that you can do with them. Once I learned that there's a certain logic that you could follow, I could figure it out for myself without someone helping me. [...] I could say "I'm in control now". So...I was lost. Lost in the street somewhere. Lost in a way that you cannot use and do what you want to do.

Irena's reflection evokes Heidegger's (1977/1993) notion that a person's lack of familiarity with using technology makes it less accessible. This is because its intended purpose or potential is both inherent and hidden in its purpose and the way it is made to fulfill that purpose within a particular socio-cultural context. This is what Heidegger terms the enframing of technology. A technology's enframing can be more or less known to us depending on our understanding of, and ability to tap, a technology's standing reserve. Standing reserve is the actuating potential of a particular technology. This can be only accessed in relation to its enframing or intended use (Heidegger, 1977/1993, p. 329). Heidegger provides an example of this concept:

[A]n airliner that stands on the runway is surely an object. Certainly. We can represent the machine so. But it conceals itself to what and how it is. Revealed, it stands on the taxi strip only as standing-reserve, inasmuch as it is ordered to insure the possibility of transportation. For this it must be in its whole structure and in every one of its constituent parts itself on call for duty, i.e. ready for takeoff. (Heidegger, 1977/1993, p. 322)

Corresponding with this analogy, a student who hadn't ever used a computer wouldn't likely recognize its capacity to assist with composing an essay, among a myriad of other possibilities.

Notably, however, all of the international students I interviewed had used computers before coming to Canada to study. Eventually, after many months, they felt that had learned how to tap the potential of computers for their studies. Leo's reflection on his later experiences with technology opens to this expanding knowledge and skill in using technology:

So I learn by the day, you know, everyday something new. And that is what makes me feel the computer is now my friend. [...] I feel the satisfaction that I'm able to present something looking nice. [B]efore then, I never would present my handout like that. I would type 
everything. [...] So now I feel I'm also doing justice to the group. [...] What I have come to appreciate here is that, you see, when you are typing it yourself, you have control over the final product. [...] [Y] ou still have a chance as you are typing to change. And that is the friendliness I feel about the computer. Knowing it myself.

Leo's reflection reveals his adaptation to the academically and socio-culturally embedded nature of technology in his post-secondary environment. We cannot, however, take for granted that international students seeking help with using technology comprehend the ways it is interwoven with the intercultural lifeworld of their institution. It is much more likely that, as help providers, we encounter students who appear capable of using computer technology. At the same time, we might be perplexed by students' limited application of computer software in assignments or by the urgency expressed by students facing challenges with using computers for academic purposes.

\section{Plural potential, multiple meanings}

Arguably, we all have had lived experiences where technology breaks down of its own account, as far as our own experience is concerned. Perhaps the most commonly shared lived experience is that of 'losing' a document, as captured in an anecdote related by Abul:

I tried this way. I tried that way. Nothing worked. But the problem is that the one command I don't know and that is why I faced a lot of problem that night. [...] Actually I lost the whole document. [...] I was helpless that night, you know.

The juxtaposition of an intentional, instrumental and integrated human-technological activity with a dysfunctional, helpless, or splintered relation founds the core of phenomenological literature on technology. Whether it is the click of a mouse, the touching of a screen, or speaking to a mobile device, an instrumental intent remains: by using some form of human-computer interaction, we seek to identify an icon, characters or commands to achieve a goal. At a granular level, it is through the utilization of an English language word processing program that a student at an Anglophone, North American post-secondary institution is able to undertake his or her transformation of learning materials and experiences into an expression of his or her knowledge and skills. While such transformation may be an end result, it is the engagement with computers that constitutes the lived experience of interest here.

One of the most cited examples of embodied relations with technology is that of Heidegger's (1977/1993) hammer. The hammer represents a tangible piece of equipment meant for a fairly specific task. We pick up a hammer and use it with the intention of hammering, since it was constructed with this purpose in mind, and all other devices or implements associated with it, such as nails. For Heidegger, a tool's brokenness opens to us the intended, specific function of that tool; however, it “always comes too late” (Heidegger, 1977/1993, p. 329). When we have a broken hammer and try to find a replacement, we discover that almost everything else is unfit for the task. Merleau-Ponty (1945/2004) further explores how tools are not only known to us in their usefulness, but become integrated into our perception as consciousness-in-the-world: through using a hammer we are able see and feel the nail and the board. He wrote: 
To know how to type is not, then, to know the place of each letter among the keys, nor even to have acquired a conditioned reflex for each one, which is set in motion as it comes before our eye. [...] It is knowledge in the hands, which is forthcoming only when bodily effort is made, and cannot be formulated in detachment from that effort. (p. 166)

For Merleau-Ponty (1945/2004) technological tools, such as a keyboard, gradually become "transplanted" into "the bulk of our body" through repeated use over time (p. 166). For those who have limited experience using computers in their academic studies, or who come from countries with different keyboard designs, the standard QWERTY keyboard however might be a physical obstacle to self-expression. For example, Oba was discouraged when she realized the importance of typing speed to succeed in her studies:

I remember once we had a law discussion in the law library and everyone had a computer. And people were just typing away. I’m like, “What?” Because everyone was [...] fast. [...] [Y]ou can't keep up with the speed, you know. [...] We just started using it often when we got here. So we're kind of not there yet. We're not on the same level.

Oba's reflection brings a different awareness of the technological life-world of a Canadian campus, where "everyone has computers" and people are "just typing away." Oba came from a place where computers were largely restricted to computer labs for introductory computer courses, or accessed at Internet cafés. She was not a novice and certainly did not lack the intellectual ability to use a computer. However, she lacked the embodied skill to use a keyboard and therefore "not on the same level" as her peers.

For Ihde (1990) interaction with a keyboard also has a hermeneutic aspect. With our experience using the keyboard/mouse, we can come to know the purpose of "shift-keys" (such as "Control $+\mathrm{S}$ " to save a document) or the right and left click and scroll button of the mouse and we use these according to their function in a computer program. This becomes habit for us, in the way Merleau-Ponty (1945/2004) describes habitual action. Ihde (1990) terms this "hermeneutic transparency," experienced as a kind of “acute perceptual seeing” (Ihde, 1990, p. 94). Developing one's knowledge of and skills in using computers comes from repeated use and integration into one's life-world. With access and experience to computers, a student is more able to understand the logic of the software program. As Irena noted, once she had "learned that there's a certain logic" to the different technologies, she "could figure it out" for herself "without someone helping" and she could feel more "in control" of the technologies within her learning environment.

Ihde (1990) explains the nature of this kind of "seeing” as follows:

Acute perceptual seeing must be learned and, once acquired, occurs as familiarly as the act of seeing itself. For the accomplished and critical reader, the hermeneutic transparency of some set of instruments is as clear and as immediate as a visual examination of some specimen. (p. 94)

Lacking this acute perceptual seeing can lead to misapplication, or missed application, of computer software or other technologies. Leo reflected on a number of such experiences from manually counting words in his document to retyping text instead of using the "cut and paste" function. In this recollection, he discussed how he laboured over page numbering: 
I didn't know that there was a place you could just say "insert the page numbers", you know? So I would type the page here and then it shifted one line...displacing in my whole work, and I needed to redo it, and then they are taking 14 pages from you. Because you have one line there, they combine the page numbers that you needed to redo the whole thing, trying to eliminate the few lines here and there. So that was all a drain on me. The amount of time I spent doing one little thing. On top of everything else. Having to read and gather facts. The most frustrating aspect was just even to draw, even just the typing. My previous knowledge [is] from a typewriter.

While Leo was able use a typewriter, the functionality of the computer keyboard and mouse in relation to word processing software was not hermeneutically transparent and created challenges for him.

Our hermeneutic relation with computers also affects the nature of our research, testing and assignment completion in post-secondary institutions. For Ihde (1990), new technologies provide "a framework for action" that affects the "intentionalities and inclinations with which usepatterns take dominant shape” (p. 141). Ihde (1990) illustrates this by discussing the way the editing process has been affected by word processing software:

[...] The electronic word processor poses a different instrumental framework and set of possibilities and is now the favoured instrument of many academics. What stands out here is the transformation of the editing process. That has become much easier than with either of the previous technologies, given the ability to re-letter and move whole blocks of sentences around. [...] Precisely because the editing process is made easy, composition now provides a focal temptation. The ease of rewriting becomes a way to see the whole project as more malleable and thus unfixed. (p. 142)

Writing and writing assessment are altered by standardization of format and style, ease of access of research articles and essays, integration of referencing and citation programs. Through the standardization of word processing tools, dominance of certain normative practices emerges. The Western "Germanic tome" (Ihde, 1990, p. 142) and the academic cultural construct of citation, end-noting and/or footnoting has become embedded in word processing software. Western notions of academic style and integrity (i.e. intellectual property) are assumed in its fulsome use. Consequently, we might think that because a student can functionally utilize word processing software, he or she also understands its cultural academic application. However, it is possible for a student to have well developed knowledge and skills in using computers for specific purposes, but to differently interpret the cultural hermeneutic of its multiple academic applications.

For Ihde (1990), the variability of technology is due to its existence as a "[m]ultistable phenomenon" full of "ambiguity and multiple dimensions" (p. 150). Ihde (1990) concludes that such ambiguity and multiplicity are enabled by the manner in which modern communications are made "hermeneutically simple and virtually interculturally available" (p. 155). An example of this is the similarities in the layout and functionality of different smart phone and tablet devices. From an intercultural perspective, accessing such information and communications technologies may require "short hermeneutic learning processes", once a person has developed an understanding of the logic of the computer interface and functionality of the devices. Ihde (1990) argues, however, that this often leads to a hasty, superficial analysis and determination of technology transfer. Increased access to and perceived similarity of modern communications devices create a false 
semblance of neutrality and universality. As communications technologies are adapted within the technological life-world of different peoples, regions, cultures and nations, variability in use is made manifest. This reflects what Ihde (1990) terms the "non-neutral" pluricultural pattern of modern technologies, part of an "inclination, not a determination of technology" (p. 156).

The inclination of technology within different contexts includes the patterning of help seeking and help giving. For example, Aline recalls her experiences of trying to log on to her wireless internet service at her university:

They turn the computer towards you, "Just click on that and then after that you type in your password and your ID, and you're good to go.” And you'd be like, "Right. I don't have a computer and ID”. "Oh you can't use these computers without a computing ID. So you have to go to the something, something services and you have to get it from there". [...] "I don't know where that is". "It's in the something, something, something, um, two floors." [...] By then you probably will give up. [...] You first forget, not even that, you have to go get your computer pass ID. By the time you come back and try to use the computer you won't know what you have do. And if you go back, she'll probably look at you, [and say] "You've forgotten already?"

Aline had used computers outside of the technical and bureaucratic categories of large Canadian campuses. Her reflection illustrates how a transactional, technologically-integrated "service" lifeword can feel as a newcomer. In her recollection, Aline wants help solving a nested set of questions related to a technology problem. Instead of working through these questions with her help provider, she feels talked at and directed to undertake the impossible. Then, when she realizes she doesn't understand, she feels like giving up because she doesn't want to be seen as incompetent. Is it the technology that leads to her feeling this way or is it the support system or the approach to assistance and instruction? If it is the latter, then the role of pedagogy comes into play.

\section{Demonstrated potential, ethical meanings}

Help giving with students new to computer technology must therefore ensure shared comprehension of the embodied human-computer interaction to achieve acute perceptual seeing and access the rhetorical (navigational) and practical logic of the software. However, this help giving advice lack attention to the relational aspects that aid in achieving shared comprehension. Irena's reflection on an early help seeking experience with a computer lab help provider reveals how a poor helping, or pedagogical, relation can negatively affect a student's learning:

At the beginning, you would say something in English and it would just go out. In one ear out of the other ear. [...] And this guy would try to help me, "OK, Control-M that's a new slide”. He would do it right away and I was trying to see what keys he would press. I was trying to see what happens with the screen and understand his explanation. [A]fter he left, I would go and try and do whatever he showed me and I would catch most of it, but some of them I would say, “Oh, I have to ask him again.” Because maybe he didn’t realize that it takes me awhile to see what he does with his fingers, "Control-M" it's a new slide. Well, it doesn't make sense to me. 
In a technology help seeking and help giving context, there are two (or more) people who are trying to make sense of the problem to be solved. The relationship is, however, asymmetrical, in that the help provider presumably has the knowledge and skill while the help seeker does not. At the same time, the help provider must take on a role of assuring the student that he or she is listening and is responsive to what the student does or does not understand. While oriented to the lived relation between teachers and children, Bollnow's conception of trust and confidence has conceptual value here. According to Henriksson (2012), Bollnow views confidence as "one-sided" and relates to "mostly cognitive abilities", whereas trust "is relational and demands a response and refers to the emotional bond" between the teacher and student (p. 127). She goes on to say that,

Even though the pedagogical relationship is a reciprocal one, it is at the same time an asymmetrical relationship, in which the teacher is responsible for the student's intellectual and emotional growth (Henriksson, 2012, p. 127)

Thus, while helping oriented actions would be intricately tied with the hardware and software, a help provider must also be attentive to whether the student is following the guidance being given. If the student is a novice with technology then little should be assumed or taken for granted and patient, hands-on demonstration and practice are critical to ensure shared attention and thereby increase the student's familiarity with the computer. This requires pedagogical tact, defined by van Manen (1991) as "holding back" with "an openness" to the student's experience” and an "attunement" to his or subjectivity while at the same time exerting a "subtle influence" as "situational confidence" and "as an improvisational gift" (p. 149). This may be illustrated by the kind of lived relation Samiya has with her husband, who is also her primary help provider:

He keeps showing me how to proceed. [...] If you do this kind of thing and go through this, you will be able to figure out the solution. Actually, he's showing me on the screen. It goes both ways. Sometimes he does and I watch how he does and sometimes he sits beside me and then tells me "This is the step. Go on this. Go on [and do] this."

Samiya's interaction with her husband includes a level of calmness and confidence that is quite different from other points in her studies, where she felt "lost", "sick" and wanting to quit. Being shown how to use technology in her own language addresses her subjectivity. However, while language, intimacy or cultural similarity may have contributed to Samiya's positive experience, for all participants, such characteristics were not essential to good help giving. It may be inferred that if Samiya's husband was impatient or insensitive, their shared socio-cultural and linguistic heritage would not necessarily have been of value. It is her help provider's demeanour that mattered most.

In that vein, one of Irena's most poignant recollections of good help was neither from from a family member nor from an official "help provider"; rather it was from her landlord who took an interest in her success. She recalls:

I was asked in the very first days to make a one page statement in English. I could barely speak English at that time. [...] So I was a little scared and I went and talked to her [her landlord] and she said, "Write down however, whatever. Put it on paper on the computer anyway and we'll go through it and I'll show you what, how to arrange on the page and format it or maybe words, spelling." 'Cause I didn't know that you could spell check, I 
didn’t know all this stuff that the computer actually does for yourself. [...] I would be here at the computer and she would look over my shoulder and make sure that everything looks good, is spelled good, properly. [...] Sometimes, for instance if I couldn't find a tab or something, she would show me, “OK here, you go there.” [...]She’s not fast. She...I don’t know. She just has a way of explaining very well.

Irena's recollection reveals the lived meaning of discretion and subtlety in pedagogically tactful help provision. Discretion is not only a matter of language; it is also felt through being in a private space or being helped by someone who is trusted, who will not form a negative judgement and who is able to adapt or improvise how he or she provides assistance. None of the participants shared positive stories in which they visibly sought technology assistance in the midst of a large group. Their anecdotes related lived experiences receiving good help by someone in their home, in the next office or at the next computer, by a peer, a discrete help desk officer, or by a known staff person within their department. Aline described how this private helping space felt for her in a lab that had separated cubicles with a computer lab assistant she had come to trust:

I'm the only one there and if I'm making a mistake or don't know how to do something I could, or when I get help, [...] it feels like just me and the person alone looking at the computer. [...] When you have your own space, your own cube, it's like, there's only the two of you [...] and the computer. And so, it's like a partnership in between.

Feeling "in your own space" and in "partnership" with a help provider is an affirmative lived relation. For the students, the opposite of this affirmative lived relation is that of condescension and conspicuousness. This was experienced through direct statements, body language or insinuation. Irena, for example, related a difficult period in her first year of studies where her peers who had offered her help ultimately criticized her for being "high maintenance”. The participants' reactions to such experiences ranged from avoidance to anger. Mafi expressed these mixed emotions:

You ask the person once. The person doesn’t help before in the past. And the second time, maybe the help is not forthcoming. You just automatically - your mind zeroes against this person. Sorry, I am not lying. Sometimes it's a matter of "I'd rather rot and have a lot of problems than thinking of asking this person". Sometimes fright comes in, too. Or sometimes, you just can't help it.

It is instructive to consider these quotes in context to Friesen's (2012) discussion on the pedagogical significance of the intersection between the "I", "It", "You" and "We" in phenomenological analysis. The "I" is the feeling, thinking, sensing self who reflects upon lived experience, disclosing the lived existentials of those experiences. The "It" is the objective, natural world, which in this article is refers to computers, or the physical post-secondary learning environment. The "You" is an ethical stance of lived in relation to others. The "We" is the intersubjective meaning shared across lived experiences, including through phenomenological writing.

In Mafi's reflection, the only phrase in which he used "I" was, "I'd rather rot and have a lot of problems than thinking of asking this person". This is an isolated "I" in context to the "You", which was the student from whom he had asked for help. This "You" is incorporated into how Mafi experiences his "I"; a relationship of fear and disconnection. Irena's description of her 
computer lab help provision as compared to her landlord's also presents a difference in the relationship between "I" (Irena) and "You" (help provider). In the case of learning PowerPoint, Irena recalls that "this guy would try to help me", whereas in learning how to use a word processing program with her landlord, she recalls that "I was a little scared and I went and talked to her." In the first instance, the "You" is ambivalent and disinterested; in the second instance, the "You" is someone that Irena sought in order to alleviate her fears. For Irena, "I", "It" and "You" were combined in a memory of help seeking that led to a long term relationship with her landlord. This inter-subjective relation moves to "We", and is evident in Aline's recollection, where she brings together all four relations with the words "it's like a partnership between”.

What does it mean, then, for professional help providers at post-secondary institutions if technology help seeking for international students includes a search for "partnership" or a trusting friendship with someone, such as a landlord? This collegial or mutual connection arguably goes beyond pedagogical tact. The pedagogical relation between "I" and "You" in the North American help giving context tends towards respect for individual autonomy and achievement, which can be in conflict with other socio-cultural helping approaches (Cox \& Strange, 2010; Pope, Reynolds \& Mueller, 2005). Explaining the lived meaning of technology help seeking and giving for international students may therefore also embrace reciprocity as a form of indebtedness or "gifting” (Sahlins, 1997) in lived relations with help providers. In an intercultural community of student life, this may be the most important lived relation of all.

\section{Reciprocal potential, shared meanings}

Many students note the dissonance between their past and present help seeking environments. In an early reflection, Aline described her frustration with the "professional" nature of help provision in her institution, as compared to her past experience:

Well, here tend[s] to be more professional. [B]ack home everybody is laid back. [...] When you go to a desk [...] like the one downstairs and you ask for help, they just give you the one-two-three, the basics. [...] It's not very informative. [...]

Vlad also compared the "time efficient" North American learning environment to his past experience:

I noticed a difference, because I come mostly from a collectivistic society where people, you know, share everything. If my neighbour had a computer we would share it and, you know, we would go and spend time, and here it's more individualized. So if you need to get help here, you need to really set an appointment [...] and talk in advance about getting help. While back at home it will be impromptu. You just come in and share the computer. [...] It's not that you have to say, "Look, I'll come [at] five o'clock.” There's nothing wrong with it. It's just that you respect somebody's time.

In his new learning environment, Vlad feels he must work more individualistically and "respect" people's time through setting appointments. Irena, on the other hand, candidly expressed another source of discord - that of being perceived as incapable by her professors: 
Well, I would say, first, I didn't know anybody official paid to do...to teach me how to use computers [...] There wasn’t anybody...[...] [I]n my culture, you do not ask professors, or you do not ask seniors I would say. You try and find out the things for yourself with your friends, with your parents, whoever you have close, and then if that doesn't work, then you might go to the professor and ask. But if you do that, they might think, "Why are you here? It's not your place if you don't know what you're doing."

Irena also relayed turning down an offer for assistance, as in her culture, it would be rude to have said yes the first time. However, in North America, "no" means "no", and so, she was shocked when her prospective help provider walked away after only offering once to assist her.

In this sense, the offer of technology assistance is quite different than its request. To feel as if assistance is offered is to see it as a gift. It is something that might be (or should be) reciprocated. In this view, reciprocity may be viewed as a form of free "market" of help giving, satisfying future expectations for assistance from other students (Sahlins, 1997). This is significantly different from a client "service" model of student support, where the "gift" becomes a commodity: a "market" exchange through tuition fees for a set of services, entwined within bureaucratic hierarchical relations (Bourdieu, 1997). As a client service orientation becomes integrated into the institutional help giving culture, it becomes its habitus (Bourdieu, 1997), framing help seeking and giving with certain socio-cultural conventions. As technology permeates so many aspects of student life, this approach to help provision may create a sense of being a passive recipient of help, or as Irena experienced, feeling like one is "high maintenance" or a burden to others.

For example, Aline describes an experience she had with a spontaneous, student-directed, collaborative technology support approach. She recalls:

You know what they did to us? We had to attend a four hour class about filling in our tax forms with this girl talking throughout four hours. Do you know how brain damaging that is? And then you come out of the class, you feel nothing. You even forget the first thing she said. But thankfully there are these students [...] in the same group I was in and they were like, you know, "We are offering help". You can come to [this classroom] and they had two computers, each side-by-side and we fill it in with you, you know, we do it together [...] [T]hat's what I call good help.

As opposed to the "brain damaging” presentation by a formal help provider, Aline experiences freely provided help by her peers. From this peer help, she feels connected, successful and satisfied. Irena also touched on the reciprocity of peer-to-peer support, when she compared her experiences of formal and informal technology support contexts. A difficulty she faced was that her challenges with the software intersected with her (mis)understanding of her assignment. In seeking professional assistance, she felt there was a glass ceiling for help. Official help providers would say that he/she wouldn't be able to provide any further help because it would either take too long and/or be a form of academic dishonesty. The exchange was asymmetrical in a manner that prevented her from achieving the level of mutuality she was seeking. In contrast, Irena described what it was like for her to have proximity with her peers in her lab, where help could be reciprocated easily: 
Our lab was separate [from] most of the other graduate students, so...we knew each other better and we spent a lot of time together, doing assignments for different classes. But we would have the chance, each of us, to ask just like that. You're typing and suddenly there's a question, you know, "So what should I do here? What should I say? Is this correct? Is this not?" So...that was a group, like a community, right? A little community that was supportive to each other.

Vlad also shared an anecdote that presents the feeling of obligation or reciprocity in receiving and providing good help, especially that which comes unexpectedly:

One student who helped me with iMovie, stopped by and said, "Have you submitted your marks for the class?” And I said, "Not yet. I have a problem. I can't submit them.” So he said, "OK, if you experience the same problems let me know and I'll try to figure it out and I'll tell you." So a couple of hours later he said, he came back and said, yeah, "You have to save the marks first and then submit them.” Because he couldn't submit them and then I passed that on to another colleague who I knew would be submitting the marks himself pretty soon so, you know. That was the sharing. [...] Sometimes it's not asking for help. It comes to you.

In anecdotes such as these, giving help with using technology is connected to how help is received and reciprocated. For Vlad this also extended to online help, which he regularly consulted as he became more confident with using different software. For students in this study, help seeking was related to help giving, insofar as their lived experience was a lived relation involving passing along needed knowledge, skills and shared resources. Leo describes just how deeply this reciprocity can delve into an international student's lived relations with his or her peers.

You feel a commitment. [...] Somebody is in trouble, so you commit yourself to it and then you feel a kind of satisfaction. [...] You are being able to help somebody around a problem you were experiencing before. [...] Being as patient as possible, as slow as possible, and to always ask, "Do you understand? If you don't understand, come back." And then sometimes you see a task [is] very simple, because you know it now, and the person doesn't understand and you wonder why [...] But then it's always at the back of my mind, "Be as slow as possible. You were there before”. [...] [T] his is part of thing I've told myself I have to do. I have to tell myself, "Look, I shouldn't get frustrated with them. It's not their fault. Be as much help as possible. Somebody did it for you”.

Students shared their sense of mutuality through genuine and generous expressions of indebtedness to their help providers, be they students, faculty or staff. Such reciprocity and shared meaning extended beyond technology and into other facets of the students' lives, resulting in friendships or a commitment to help others in similar circumstances. In terms of help provision with technology, what this means can be simply stated: assumptions regarding international student help seeking, based upon what van Manen (1991) termed “a technical production process, with inputs, treatments and outputs” (p. 105) may result in empty computer training sessions and poorly utilized support. Alternatively, learning environments that foster reciprocity, shared meaning and mutuality would emphasize open-ended engagement. A pedagogical relation of help 
provision would view technology assistance as being a demand for ethical, meaningful practice within an intercultural community of student life.

\section{Conclusion: Phenomenology as a technology help giving training methodology}

With repeated questions and answers, help giving of any type can feel monotonous or unrewarding, and with more complex issues, it may feel more efficient to "just do it for the student". As a means to counteract this tendency, I have drawn from my own phenomenological research and writing to direct my help giving in an "action-sensitive” manner. van Manen (1997) describes actionsensitivity as a primary concern of human science:

$[\mathrm{H}]$ uman science is concerned with action in that hermeneutic phenomenological reflection deepens thought and therefore radicalizes thinking and the acting that flows from it. [...] [T] o become more thoughtfully or attentively aware of aspects of human life which hitherto were merely glossed over or taken-for-granted will more likely bring us to the edge of speaking up, speaking out, or decisively acting in social situations that ask for such action. (p. 154)

I have understood action-sensitivity as requiring sustained effort to deep my pedagogical and practical understanding as a help provider. This demands continual reflection upon the lived meaning of my interactions with international students. It is a practice that has led me to develop a phenomenological approach to training help providers. In developing this approach, I have collaborated with many colleagues in different campus departments, emphasizing the "intuitive, dynamic and non-rational features" of helping others (van Manen, 1991, p. 105). There are four aspects to the approach that I will discuss in this conclusion: the use of the phenomenological interview; the exploration of inter-subjective life-world identity; the incorporation of imagination in an action-sensitive life-world; and the phenomenological emphasis on tone, listening/observation and reflective practice.

The starting point includes a form of phenomenological interview that presents "fill in the blank" questions regarding help seeking, such as "When I seek help from a professor on an assignment that I am having difficulty with, I feel...", or "Seeking help from a professor on an assignment on a topic I don't understands means that I am....” I also include these same questions, but incorporate new identities, such as "When a new international student from a very different cultural and learning environment seeks help from a professor/peer, he/she feels..." Participants work in pairs and have words available on the handout to help start the discussion. The intent is to help orient the group towards lived body, space, time and relations, and to challenge assumptions, without stating so directly. These are incorporated into the words themselves. Anecdotal questions are also included, such as: Can you remember a time when you received excellent/poor help? What do you remember about this experience that makes it so memorable? How did you feel? What do you recall about the space you were in? What do you recall about the way that your help provider supported you? These paired discussions are then debriefed as a group and we discuss the lived experience of help seeking from the perspective of a diverse, intercultural learning environment.

A second activity involves the exposition of through what I term an inter-subjective lifeworld identity. This requires the completion of a form with questions including an "imaginary" student's name, age, gender, family status, field of study, travel experience, hobbies, fears, sources 
of pride, languages spoken, and then specifics to the help seeking context, such as knowledge of technology, experience using technology, level of technology access at home, etc. This is a paired activity and, included in the profile, are questions for the participants to discuss together. Examples are: "What is a stereotype that this student must deal with regularly? What is a pattern of experience this student has in relation to working or studying in groups? What do this student's closest friends say about him/her?" The participants must both fill out the form for this imaginary student. These pairs are then separated into groups of four participants, each with a different imaginary student. These small groups are asked to discuss questions such as, "What is realistic about this imaginary student? What seems unrealistic? Why do you feel this way?" After participants have shared their profiles, we engage in a large group discussion. Participants share profiles and discuss what was realistic or unrealistic and how they felt during the process of developing their profile. I ask the group what other questions they might want to ask, emphasizing inquisitiveness and interest in the lived experience of others. This provides an opportunity to explore the challenge and potential of understanding and transcending, through experience and reflection, the limits of our intercultural knowledge and skills, such that we may develop a deeper awareness of and capability to meet the needs of a diverse student population.

I then have the participants work in their groups and discuss different scenarios. In the case of technology help seeking and giving, this includes examples such as, "One of these students is sitting at a computer in the library learning commons and is having difficulty with a computer application. How would you approach him/her as a help provider? What might happen during this interaction? How might the student feel? How might you feel? What would make this a positive help seeking and giving experience for both of you?" This set of questions may be used for two to four of the imaginary students in order to explore how each interaction might be similar or different.

This leads to a discussion on phenomenology as practice. In the intercultural context of help seeking and help giving on campus, I discuss how assumptions and tone impact our lived relations. As part of this, I integrate 'facts' into the presentation, such as statistics regarding student enrolment and library or student service usage by different student demographic groups. I have this as a set of true/false or multiple choice questions in order to open the dialogue on what we feel we 'know' and what we 'experience'. This enables participants to consider how their lives may or may not be socio-culturally isolated, such that they are not 'seeing' or 'experiencing' diversity. I also often integrate anecdotes focused on help seeking and help giving from my research, and from other qualitative research or fiction. I have also integrated art that helps evoke an emotional or psychological response, such as Edvard Munch's painting, The Scream. The Scream provides a means to depict the existential moment of feeling helpless, when help may or may not be available. In Munch's series of paintings, a person stands alone, lost, anxious, afraid, as if his or her call for help swallowed in a vacuous tunnel, while in the background, one can see passers-by, seemingly unaware of, or unaffected by, his or her suffering.

What I have asked, and continually ask myself as a professional in my field is, Why do some students feel such helplessness, while their peers mill about in the hallways and while support staff and faculty are able and willing to help them? What I have come to feel is that unfamiliarity with their surroundings, including the technological life-world of their new learning environment, conceals the support that can be provided by another. This image opens dialogue to the shared lived meaning of being lost; a metaphor that I have found is often used by international students in relation to adapting to their new, technology-infused learning environment. This metaphor recasts the concept of help giving from an instructional or remedial role to one of a guide, to one 
who is seeking to find the intended directionality of each student seeking assistance. This role requires a commitment to seek understanding as to how each student has arrived at that particular place in his or her life journey, including his or her search for an intercultural community of student life.

\section{References:}

Bourdieu, P. (1997). Selections from The Logic of Practice. In A. Schrift (Ed.), The logic of the gift: Toward an ethic of generosity, (pp. 190-230) New York, NY: Routledge.

Cox, A. \& Strange, C. (2010). Achieving student success: Effective services in Canadian higher education. Montreal, QC: McGill-Queen’s University Press.

Crosby, A. (2010). The International Student Experience in Canadian Post-secondary Education: Democratic racism, anti-racism education, and internationalization at home. Our Schools, Our Selves; Spring 2010; 19, (3), pp. 399-413.

Donati, P. (2013). Relational sociology: A new paradigm for the social sciences. New York, NY: Routledge.

Friesen, N. (2012). Experiential evidence: I, we, you. In N. Friesen, C. Henriksson and T. Saevi (Eds.), Hermeneutic phenomenology in education: Method and practice (pp. 39-54). Boston, MA: Sense Publishers.

Gadamer, H-G. (2004). Truth and method. New York, NY: Continuum. (Original work published 1975).

Greene, M. (1973). Teacher as stranger: Educational philosophy for the modern age. Belmont, CA: Wadsworth Publishing Co.

Grossman, R. (1984). Phenomenology \& existentialism: An introduction. New York, NY: Routledge \& Kegan Paul.

Gay, G. \& Hembrooke, H. (2004). Activity-centred design: An ecological approach to designing smart tools and usable systems. Cambridge, MA: The MIT Press.

Heidegger, M. (1977). The question concerning technology and other essays. New York, NY: Garland Publishing, Inc.

Henriksson, C. (2012). Hermeneutic phenomenology and pedagogical practice. In N. Friesen, C. Henriksoon \& T. Saevi, (Eds), Hermeneutic phenomenology in education: Method and practice (pp. 119-137). Boston, MA: Sense Publishers.

Husserl, E. (2002a). The way into phenomenological transcendental philosophy by inquiring back the pregiven life-world. In The phenomenology reader, D. Moran \& T. Mooney (Eds.), pp. 151-174. New York, NY: Routledge. (Reprinted from The crisis of European sciences and transcendental phenomenology: An introduction to phenomenological philosophy, D. Carr, Trans., pp. 103-137, 1970).

Husserl, E. (2002b). Pure phenomenology, its method, and its field of investigation. In The phenomenology reader, D. Moran \& T. Mooney, (Eds.), pp. 124-133). New York, NY: 
Routledge. (Reprinted from Husserl shorter works, pp. 10-17, by P. McCormick \& F. Elliston, Eds., 1981).

Ihde, D. (1990). Technology and the lifeworld: From garden to earth. Bloomington, IA: Indiana University Press.

ITU-D (2010). Measuring the information society: 2010. Place des Nations, Switzerland :International Telecommunications Union - Development. Retrieved from http://www.itu.int/ITUD/ict/publications/idi/2010/Material/MIS_2010_Summary_E.pdf

Lee, J., \& Rice, C. (2007). Welcome to America? International student perceptions of discrimination. Higher Education, 53, 381-409.

Madgett, P., \& Bélanger, C. (2008). International students: The Canadian experience. Tertiary Education and Management, 14(3), 191-207.

Merleau-Ponty, M. (2004). Phenomenology of perception (C. Smith, Trans.). New York, NY: Routledge. (Original work published 1945).

Pope, R. Reynolds, A. \& Mueller, J. (2004). Multicultural competence in student affairs. San Franscisco, CA: Jossey-Bass.

Paulus, T., Bichelmeyer, B., Malopinsky, L., Pereira, M., \& Rastogi, P. (2005). Power distance and group dynamics of an international project team: A case study. Teaching in Higher Education, 10(1), 43-55.

Robson, S. \& Turner, Y. (2008). Internationalizing the university. New York: NY: Continuum International Publishing Group.

Saevi, T. \& Friesen, N. Reviving forgotten connections in North American teacher education: Klaus Mollenhauer and the pedagogical relation. Journal of Curriculum Studies, 42(2), 123147.

Sahlins, M. (1997). The spirit of the gift. In A. Schrift (Ed.), The logic of the gift: Toward an ethic of generosity, (pp. 70-99) New York, NY: Routledge.

Tannis, D. (2010). International students' lived experiences seeking ICT assistance: Just click here. (Unpublished master's thesis). University of Saskatchewan, Canada.

Turkle, S. (1994). Life on the screen: Identity and the age of the Internet. New York: Touchstone.

Unterhalter, E. \& Carpentier, V. (2010). Global inequalities in higher education: Whose interests are we serving? London, UK: Palgrave MacMillan.

van Manen, M. (1991). The tact of teaching: The meaning of pedagogical thoughtfulness. Albany, NY: State University of New York Press.

van Manen, M. (1997). Researching lived experience: Human science for an action sensitive pedagogy (2nd Ed.). London, ON: The Althouse Press. 